\title{
Application of simple risk level estimator to assess the fire risk in trade zone of Nyarugenge
}

\author{
Theoneste Ntakirutimana*, Rubuga Kitema Felix, Serge Bakire, Wilma Uhorakeye, \\ Donat Tuyihimbaze, Osman Ngarukiyintwari
}

University of Rwanda, College of Medicine and Health sciences, School of Public Health, Department of Environmental Health Sciences, P.O.Box:3286, Kigali, Rwanda

Email address:

tntaki@yahoo.co.uk (T. Ntakirutimana)

\section{To cite this article:}

Theoneste Ntakirutimana, Rubuga Kitema Felix, Serge Bakire, Wilma Uhorakeye, Donat Tuyihimbaze, Osman Ngarukiyintwari. Application of Simple Risk Level Estimator to Assess the Fire Risk in Trade Zone of Nyarugenge. American Journal of Health Research.

Vol. 2, No. 6, 2014, pp. 334-337. doi: 10.11648/j.ajhr.20140206.12

\begin{abstract}
A fire risk assessment helps in determining the chances of a fire to occur and the dangers resulted from fire outbreak. Analysing the activities undertaken within the premises; the potential harm of the fire it could cause to the people in, and around the premises is an important issue. The aim of this study was to assess the risk and consequences of a fire outbreak in the trade zone of Nyarugenge. A cross sectional and quantitative methods were used in this study. Fire hazards resulting from readily combustible or highly flammable materials, sources of heat, and people at risk were studied. The likelihood that a fire will occur and the consequences of such a fire on the people in trade zone of Nyarugenge were analysed using a Simple Risk level Estimator. Based on the analysis, $92.71 \%$ of the premises had no firefighting equipments in the trade zone $83.33 \%$ of the premises had non-inspected electrical installation and none of them had smoke alarm or heat detectors. Smokers' materials ranked the highest source of ignition 26\% followed by lighting equipments 19\%, Cooking Equipment Ranked the third13\% followed by Naked flame and misused electrical equipment $12 \%$. The results of the study indicated that the likelihood of a fire in the trade zone of Nyarugenge was high and has significant potential for serious injury or death to occupants.
\end{abstract}

Keyworld: Fire Risk, Nyarugenge Trade Zone, Likelihood of Fire, Simple Risk Estimator

\section{Introduction}

Fire outbreak is one of the security concerns in Rwanda especially in cities. It has destroyed property including houses and in some cases, has claimed lives (1). A total number of 84 and 93 incidences of fire outbreak have been registered in 2013 and 2014 respectively. The majority of incidents were due to short-circuit, candles, welding and domestic electrical appliances. (1). Although many cases have been reported no research has been done on likelihood and consequences of fire out break in Rwanda.

The consequences of fire outbreak in buildings are not limited to death risk, it has killed a lot of people in commercial buildings (2). The fire outbreak can also damage the environment, disrupt economic activities and increases the problem of poverty (3).

Fire hazard is explained by fire triangle, the triangle illustrates that a fire to occur; it requires three elements: heat, fuel, and an oxidizing agent such as oxygen (4). Heat is the first element in a fire triangle that starts the ignition and maintains that combustion (5). Electrical current, heating equipment, open flames and sparks, and lightning are the major sources of heat There are many different sources of fuel in which Flammable solids such as paper, wood, plastics and waste material.The second source of fuel are Flammable liquids and solvents that include petrol, paraffin; the third one is Flammable gases that include propane, butane, and acetylene (6).

The aims of the fire risk assessment were to identify the fire hazards resulting from readily combustible or highly flammable materials, sources of heat, and unsatisfactory structural features. The likelihood that a fire will occur and the consequences of such fire out break on the people in the building of Nyarugenge Trade zone were also assessed. This paper stimulated an assessment of potential risks that would cause fire hazard in commercial buildings of trade zone in 
Nyarugenge.

\section{Material and Methods}

\subsection{Introduction}

This research was conducted using the quantitative methods; a cross sectional study design was used to assess fire risk in the building of trade zone of Nyarugenge. The questionnaire which was developed by British Standards Institution with the support and encouragement of the Institution of Fire Engineers and the Northern Ireland Fire Safety Panel, which represents building control and licensing authorities in Northern Ireland, and the Northern Ireland Fire and Rescue Service was adopted and validated in order to fit this research.

\subsection{The Study Area}

The trade zone of Nyarugenge is located in Kiyovu cell, Nyarugenge sector, one of the ten sectors of Nyarugenge districts in Kigali city in Rwanda. Trade zone of Nyarugenge is intersected by many people, workers, vehicles, trucks that are carrying products waiting to be disembarked and the place hosts many valuable materials.

\subsection{Data Collection Method}

A simple random sampling was used. The sample size was calculated using Raosoft EZSurvey 2014. It is a highly advanced new edition of easy and robust electronic data collection program (7) and the sample size representing the whole trade zone of Nyarugende was found to be 96 people. The questionnaire had three parts, the first one contains the identification of fire hazards, followed by identification of people at risk and ended up with existing fire safety measures in aforementioned study area. The ethical aspects to conduct this research were granted by the authority of Nyarugenge. All participants in the study were provided written informed consent, and confidentiality was ensured by use of study IDs instead of their names

\subsection{Simple Risk Level Estimator}

The simple risk level estimator used in this assessment of fire was from one British standard BS880; it combines the likelihood of fire and likely consequences of fire (8). The risk categories could be 'Low', 'Normal' and 'High' Low: There is hardly any risk from fire, few combustibles materials, no highly flammable substances, and virtually no sources of heat. Normal: There are sufficient quantities of combustible materials and sources of heat to be of greater than low fire risk but that a fire would be likely to remain confined, or to spread but slowly High: There is a serious risk to life from fire, or there are substantial quantities of combustible materials, or there are any highly flammable substances, or there exists the likelihood of the rapid spread of fire, heat or smoke. (8).
Table 1. Simple risk level Estimator.

\begin{tabular}{llll}
\hline \multirow{2}{*}{ Likelihood of fire } & \multicolumn{3}{l}{ Potential consequences of fire } \\
\cline { 2 - 4 } & Slight harm & Moderate harm & Extreme harm \\
\hline Low & Trivial risk & Tolerable risk & Moderate risk \\
Medium & Tolerable risk & Moderate risk & Substantial risk \\
High & Moderate risk & Substantial risk & Intolerable risk \\
\hline
\end{tabular}

Slight harm: Outbreak of fire unlikely to result in serious injury or death of any occupant (other than an occupant sleeping in a room in which a fire occurs).

Moderate harm: Outbreak of fire could foreseeably result in injury including serious injury) of one or more occupants, but it is unlikely to involve multiple fatalities.

Extreme harm: Significant potential for serious injury or death of one or more occupants.

\section{Results and Discussion}

\subsection{Identification of Fire Hazards}

For fire to occur there must be a source of ignition, fuel and oxygen (9). If all three are present and in close proximity, then the fire risk could increase as a result. Fire hazards falls into the first two categories, the oxygen will be present in the air in the surrounding space but also oxygen can be found in chemical form as oxidising agents or in cylinders or piped systems.

\subsubsection{Potential Ignition Sources of Fire in Trade Zone of Nyarugenge}

The potential ignition sources in Trade zone of Nyarugenge were investigated looking for possible sources of heat, which could get hot enough to ignite material found in the premises. These sources included smokers' material: cigarettes, matches and lighters; naked flames: candles , fuelled open-flame equipment; hot processes: welding by contractors or shrink wrapping; cooking equipment, faulty or misused electrical equipment; lighting equipment, such as halogen lamps or display lighting too close to stored products; hot surfaces and obstruction of equipment ventilation, e.g. office equipment; and arson

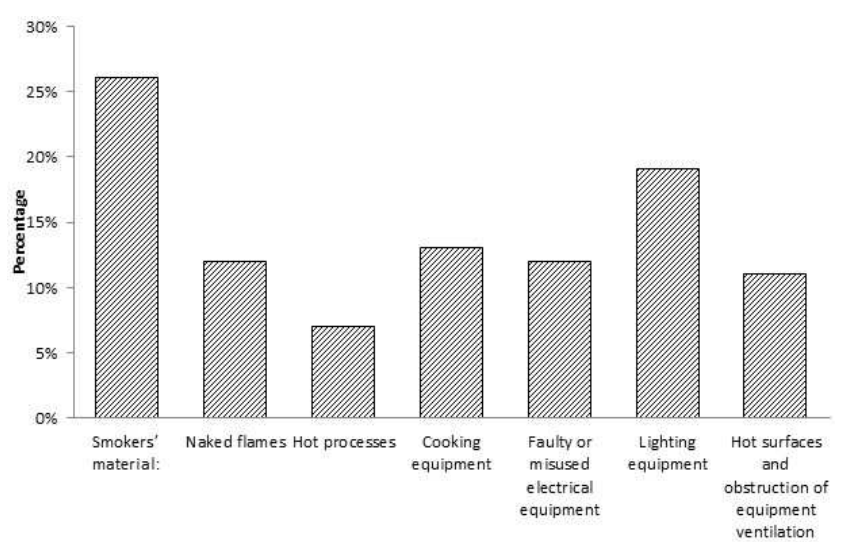

Figure 1. Potential ignition sources of fire in Trade zone of Nyarugenge 
The potential ignition sources of fire in building located in the trade zone of Nyarugenge are shown in figure 1. The results revealed that the Smokers' materials ranked the highest source of ignition (26\%) followed by lighting equipments (19\%), Cooking Equipment Ranked the third(13\%) Naked flame and Faulty or misused electrical equipment had the same rank with $12 \%$, The last two sources of ignition were equipment ventilation and Hot process with $11 \%$ and $7 \%$ respectively. There is a serious risk to life from fire due to substantial quantities of combustible materials, flammable substances that result in likelihood of the rapid spread of fire. The potential sources of ignition should be reduced by: removing any unnecessary potential sources of ignition from the workplace, properly using and maintaining all heat producing equipment, fitting electrical equipment with correctly rated fuses and circuit breakers, ensuring that sources of heat do not arise from faulty or overloaded electrical or mechanical equipment, operating a permit to work system for maintenance work involving 'hot work' such as welding or flame cutting, prohibiting smoking in areas of fire risk taking precautions to avoid the risk of arson.

\subsubsection{Potential Sources of Fuel in Trade Zone of Nyarugenge}

The potential sources of fuel identified were solids liquid and gases (Figure 2). Solids included textiles, wood, paper, card, plastics, rubber, and furniture, fixtures/fittings, packaging and waste materials. Liquids were solvents paints, varnish and adhesives and acetylene as a gas: The Potential sources of fuel for a fire in the building of trade zone of Nyarugenge were studied and analysed, solids ranked the highest $70 \%$, liquids ranked the second $22 \%$ and gases was the lowest $8 \%$. The potential fuel for a fire should be minimised by replacing flammable materials with less reducing flammable materials in the workroom to a minimum required for operation of the business, storing flammable materials in separate fire resisting stores where appropriate and storing highly flammable substances in suitable fire resisting cabinets. Ensuring that flammable materials (liquids, gases and solids) are stored transported handled and used properly.

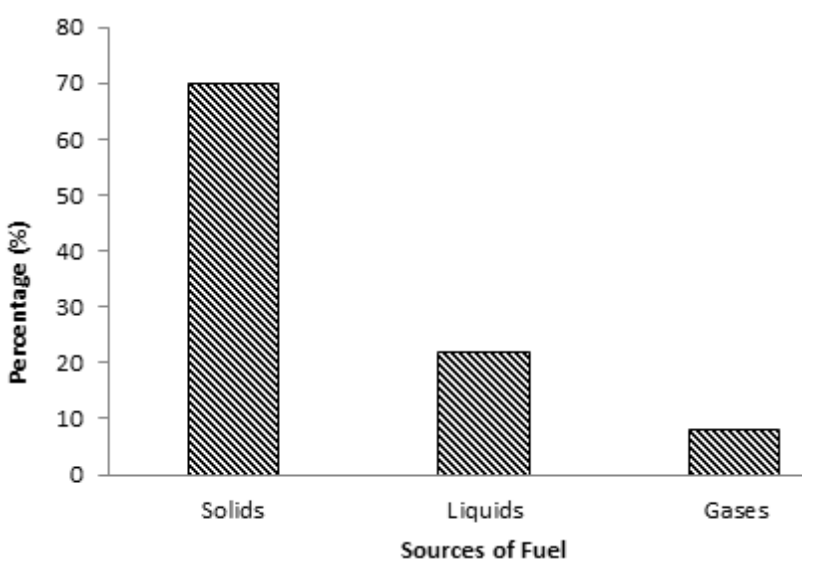

Figure 2. Sources of fuel in the trade zone of Nyaugenge

\subsubsection{The Sources of Oxygen}

The final requirement for a fire to burn is oxygen(10). The removal of Oxygen leads to extinguishment of fire, oxygen cannot be removed completely from the premises, but its amount can be controlled. Under normal circumstances, no need to restrict the amount of oxygen in the building unless if chemical processes are involved. However, restricting the amount of oxygen in the fire is the most effective way of extinguishing it. The potential sources of oxygen were analyzed and the way to minimize them was suggested.. If open these will allow a constant supply of oxygen. In the event of a fire, windows and doors should be closed; Ventilation and air conditioning systems and all air moving systems should be turned off immediately. The sources of oxygen should be reduced by closing doors and windows not required for ventilation and storing any oxidizing materials well away from heat sources or flammable materials.

\subsection{Risk of Fire Outbreak in the Trade Zone of Nyarugenge}

The risk of fire outbreak in Nyarugenge was assessed using Simple Risk level Estimator as a tool; it combines the likelihood of fire and likely consequences of fire. The results showed that there are substantial quantities of combustible materials, flammable leading to a high risk of fire outbreak. The potential consequences of fire in aforementioned are were also studied, the results showed there is a significant potential for serious injury or death of more than one occupants which corresponds to extreme harm. Combining the likelihood and consequences of fire results in Intolerable risk of Fire

\subsection{Fire Protection Measures}

Different protection measures such as warning systems, and firefighting equipment were investigated. The results revealed that all premises did not have fire alarm such as smoke alarm and heat detectors. The result is different from what was found in Consumer Product Safety Commission's (CPSC's) 2004-2005 survey done in US showing that 96-97\% of the surveyed U.S. households have at least one smoke this study reflect that fire alarm system were lacking This increases the risk of the consequences of fire outbreak

This study also identified the firefighting equipments. The majority had no firefighting equipments, resulting in high risk of fire, this is strengthened by the research done in United Kingdom showing that the lack of smoke alarms, fire extinguishers and sprinklers exacerbate the risk of injury from fire

\subsubsection{Fire Detecting and Warning System}

It was found that all inspected premises had no warning and detecting equipments such as smoke alarms, alarm systems and heat detectors.

\subsubsection{Firefighting Equipments}

The table 2 shows that $92.71 \%$ of the premises had no firefighting equipments, and the remaining $7.29 \%$ had firefighting equipments. 
Table 2. Firefighting equipments

\begin{tabular}{lll}
\hline & Firefighting equipments & Percentage (\%) \\
\hline $\begin{array}{l}\text { Absence of firefighting } \\
\text { equipments }\end{array}$ & 89 & 92.71 \\
$\begin{array}{l}\text { Presence of firefighting } \\
\text { equipments }\end{array}$ & 7 & 7.29 \\
Total & 96 & 100.0 \\
\hline
\end{tabular}

\subsection{Identification of People at Risk}

In identifying people who would be at risk of a fire, the consideration was given to traders or their workers who could be asleep and those who have impairments such as sight, hearing, or mobility and young people or children and are shown in table 3 .

Table 3. People at risk in case of fire outbreak in commercial premises

\begin{tabular}{lllll}
\hline Sleeping people & People with disabilities & Young under 18 & Old men above 60 & Pregnant women \\
\hline 25 & 14 & 5 & 9 & 17 \\
71 & 82 & 91 & 87 & 79 \\
\hline
\end{tabular}

The results showed that 25 people slept in the premises, 14 people had physical disabilities, 5 were young men under 18 years old, 17 were pregnant women, and 9 were old people above 60 years old (table 2). These groups of people have been shown elsewhere to be prone to fire accidents due to their inability to escape in a timely fashion (13); where the majority of sleeping occupants; linking to the lack of fire detecting and warning systems can be contended in high risk of fire, (14)

\section{Conclusion}

Fire prevention, limiting the spread of fire and smoke, extinguishing a fire has significant potential for prevention of serious injury or death to occupants and property loss in a building for a particular fire scenario. The Simple Risk level Estimator has been used as the tool for a fire risk assessment. The likelihood of a fire in the trade zone of Nyarugenge was high and has significant for serious injury or death to occupants. There is a serious risk to life from fire due to substantial quantities of combustible materials, flammable substances resulting to likelihood of the rapid spread of fire. Three sources of fires were identified and discussed. The potential sources of ignition should be reduced by removing any unnecessary potential sources of ignition from the workplace. The potential fuel for a fire should be minimised by replacing flammable materials with less reducing flammable materials in the workroom. The sources of oxygen should be reduced by storing any oxidizing materials well away from heat sources or flammable materials. Smoke spreads fast, the building must have smoke alarms to warn the occupants for the fire. Having working smoke alarms and fire extinguishers in the building can reduce the risk of injury or death in a fire. An escape ladder can also be useful as a secondary escape route from a room in case one or more exits are blocked by fire or smoke.

\section{Acknowledgment}

This study was funded by the University Of Rwanda, College Of Medicine and Health Sciences.

\section{References}

[1] MININTER. Police Reminds Public to take Precaution on fire outbreak 2014 Rwandan Police report Available from: http://www.mininter.gov.rw/index.php?id=17\&tx_ttnews\%5Bt $\mathrm{t} \_$news\%5D=619\&cHash=169a5fe7d8af52e6e8249e0ccb477d da

[2] Guanquan C, Jinhui W. Study on probability distribution of fire scenarios in risk assessment to emergency evacuation. Reliab Eng Syst Saf. 2012 Mar;99:24-32.

[3] Rafi MM, Wasiuddin S, Siddiqui SH. Assessment of fire hazard in Pakistan. Disaster Prev Manag. 2012;21(1):71-84.

[4] Grice A. Fire risk fire safety law and its practical application. London; 2009, 1-244.

[5] Hasofer AM, Beck VR, Bennetts ID. Risk analysis in building fire safety engineering. Amsterdam; London; 2007; 1-208.

[6] Thomson N. Fire hazards in industry. Elsevier; 2001.

[7] RaoSoft, 2014. Online sample size calculator Retrieved 30th May 2014.Available from:

$<$ http://www.raosoft.com/samplesize.html $>$..

[8] British Standards Institution. PAS 79 Fire risk assessment: guidance and a recommended methodology. London: BSI; 2007.

[9] Zhang Y. Analysis on Comprehensive Risk Assessment for Urban Fire: The Case of Haikou City. Procedia Eng [Internet]. Elsevier B.V.; 2013

[10] Todd C.S. Specification PA. PAS 79 Fire risk assessment Guidance and a recommended. 2007;1-120

[11] Woodruff JM. Consequence and likelihood in risk estimation: A matter of balance in UK health and safety risk assessment practice.43(5-6):345-53.

[12] Yung D. Principles of Fire Risk Assessment in Buildings, $2008 ; 1-248$

[13] Great Britain, Department for Communities and Local Government. Offices and shops. Wether by: Department for Communities and Local Government Publications; 2006.

[14] Ballesteros MF, Kresnow M. Prevalence of Residential Smoke Alarms and Fire Escape Plans in the U.S.: Results from the Second Injury Control and Risk Survey (ICARIS-2). Public Health Rep. 2007;122(2):224-31. 